\title{
Fontes do Diccionario gallego-castellano (1913-1928) da Real Academia Galega: Xoán Manuel Pintos, Eduardo Pondal, Benito Vicente Payzal ${ }^{*}$
}

\author{
Sources of the Diccionario gallego-castellano (1913-1928) \\ of the Real Academia Galega: Xoán Manuel Pintos, \\ Eduardo Pondal, Benito Vicente Payzal
}

\author{
$M^{\mathrm{a}}$ Dolores SÁNChez VALES \\ Universidade da Coruña \\ dolores.sanchez.vales@udc.es \\ [recibido 29/10/2012, aceptado 31/01/2013]
}

\section{RESUMO}

No proceso de elaboración do primeiro dicionario da Real Academia Galega, que só chegou á voz "cativo", contouse con diverso material léxico, entre eles os vocabularios de Xoán Manuel Pintos, Eduardo Pondal e Vicente Payzal. A maneira en que a información proporcionada por estes vocabularios foi utilizada, implícita ou explicitamente, para a feitura do dicionario axudará a comprender o laborioso e complexo proceso de redacción desta obra.

PALABRAS CHAVE: lingüística histórica, lexicografía, dicionario académico, Real Academia Galega.

SÁnchez VAles, Ma D. (2013): "Fontes do Diccionario gallego-castellano (1913-1928) da Real Academia Galega: Xoán Manuel Pintos, Eduardo Pondal, BenitoVicente Payzal”, Madrygal (Madr.), 16: 95-102.

\section{RESUMEN}

En el proceso de elaboración del primer diccionario da Real Academia Galega, que solo llegó a la voz "cativo", se contó con diverso material léxico, entre ellos los vocabularios de Xoán Manuel Pintos, Eduardo Pondal y Vicente Payzal. La manera en que la información proporcionada por estos vocabularios fue utilizada, implícita o explícitamente, para la elaboración do diccionario ayudará a comprender el laborioso y complejo proceso de redacción de esta obra.

PALABRAS ClaVE: lingüística histórica, lexicografía, diccionario académico, Real Academia Galega.

SÁnchez Vales, Ma D. (2013): "Fuentes del Diccionario gallego-castellano (1913-1928) de la Real Academia Galega:

Xoán Manuel Pintos, Eduardo Pondal, BenitoVicente Payzal”, Madrygal (Madr.), 16: 95-102.

\begin{abstract}
During the preparation of the first dictionary of the Real Academia Galega, which only reached to the word "cativo", a lot of different lexical material was used, among it, the vocabularies of Xoán Manuel Pintos, Eduardo Pondal and Vicente Payzal. The way the information provided by these vocabularies was used, implicitly or explicitly, for the making of the dictionary, will help you to understand the laborious and complex process of writing this book.
\end{abstract}

KEY WORDS: historical linguistics, lexicography, academic dictionary, Real Academia Galega.

SÁnchez Vales, Ma D. (2013): "Sources of the Diccionario gallego-castellano (1913-1928) of the Real Academia Galega: Xoán Manuel Pintos, Eduardo Pondal, BenitoVicente Payzal”, Madrygal (Madr.), 16: 95-102.

SUMARIO: 1. Introdución. 2. O Vocabulario de Payzal. 3. O Vocabulario de Pintos. 4. O Vocabulario de Pondal. 5. Conclusións. 6. Referencias bibliográficas.

* Este traballo enmárcase dentro do proxecto: Rede de Lexicografía RELEX (Ref. CN2012/290), "Fuentes de la lexicografía gallega del siglo XIX y principios del XX”, dirixido por María Dolores Sánchez Palomino e financiado polo Ministerio de Educación y Ciencia e os fondos FEDER (HUM2005-07473/FILO). Dolores Sánchez Vales pertence á Rede de Lexicografía (RELEX) (Ref. CN 2012/290), financiada pola Xunta de Galicia e coordinada tamén pola profesora Sánchez Palomino. 


\section{INTRODUCIÓN}

No Arquivo da Real Academia Galega consérvanse dous volumes cun título xenérico no lombo: "Vocabularios Gallego-Castellanos". Un dos volumes inclúe tres vocabularios manuscritos, o primeiro da autoría de Xoán Manuel Pintos, séguelle un de Eduardo Pondal e finalmente o de Luis Tobío Campos. O outro volume inclúe o Vocabulario de Benito Vicente Payzal e mais o de Leiras Pulpeiro.

A encadernación destes Vocabularios é moi posterior á chegada dos manuscritos á Real Academia Galega, e responde, moi posiblemente, a un espírito conservador, que pensou que esta sería a mellor maneira de que non se perdesen. Tampouco responde, pensamos, a ningunha circunstancia especial que o vocabulario de Pintos, o de Pondal e o de Tobío formen un volume e por esta orde e que o de Payzal e Leiras formen outro.

Nesta comunicación pretendemos estudar como tres destes Vocabularios, o de Benito Vicente Payzal, o de Xoán Manuel Pintos e o de Pondal pasaron a formar parte do material léxico do que se aproveitaron os redactores, ou redactor, do Diccionario Gallego-Castellano da Real Academia Galega ${ }^{1}$ (1913-1928) para a súa elaboración.

Os tres vocabularios citados foron publicados en datas relativamente recentes na revista Cadernos de Lingua: o de Eduardo Pondal foi editado por Xosé $\mathrm{M}^{\mathrm{a}}$ Gómez Clemente e Xosé Bieito Arias Freixedo no ano 1990; o de Payzal no ano 1994 por Manuel Ferreiro, e o de Pintos por Margarita Neira e Xesús Riveiro no ano 1992.

Desde o mesmo momento da constitución da Academia un dos obxectivos principais vai ser a elaboración dun dicionario e mais dunha gramática. Mandado que viña xa disposto desde a Habana e que se recollía no Reglamento de la Asociación Iniciadora y Protectora de la Academia
Gallega ${ }^{2}$ que, con data de publicación do 15 de xuño de 1905, recolle baixo a epígrafe "Título y objeto de la Sociedad", no seu artigo segundo:

Art. $2^{\circ}$.- La Asociación tendrá por objeto:

$1^{\circ}$ - Constituir en el punto que mejor convenga de Galicia una Academia Gallega ajena á toda idea política y religiosa sin más carácter que el de dar unidad al idioma gallego por medio de la publicación de una Gramática y un Diccionario; estudiar nuestras ciencias; cultivar nuestra literatura y las artes, inclusas las industriales; recoger nuestros cantos populares y nuestros monumentos arqueológicos, y realizando cuanto tienda á enaltecer y glorificar el buen nombre de Galicia.

Esta encomenda chégalle a Manuel Murguía quince días despois, o 1 de xullo de 1905, a través dunha carta do presidente da Asociación Iniciadora y Protectora de la Academia Gallega, Curros Enríquez, que repite practicamente este parágrafo e engade:

(...) tengo el honor de comunicarle á $\mathrm{Vd}$. que ha sido designado por dicha Asociación para proceder con el concurso de los Sres. D. José Pérez Ballesteros y D. Andrés Martínez Salazar de la Coruña, D. Indalecio Varela Lenzano y D. Jesús Rodríguez Lopez, de Lugo, D. Arturo Vazquez y D. Benito Fernandez Alonso, de Orense, D. Casto Sampedro y D. Víctor Said Armesto, de Pontevedra, y D. Angel Amor Ruibal y D. Juan Barcia Caballero, de Santiago, á la creación y constitución, conforme á los estatutos que ustedes crean mejores, de la "Academia Gallega" que ha de formar el Diccionario y gramática de nuestra lengua $(\ldots)^{3}$.

Disposto xa o encargo, os académicos encetan o proceso de constitución da Academia e unha vez posta esta a andar, inician o proxecto de elaboración do dicionario.

Este proxecto lexicográfico, estudado por Seoane Sánchez (1999), "nunca chegou a bo termo", pois só viron a luz 27 cadernos, quedando interrompida a obra na voz "cativo". A través das Actas académicas e do Boletín da

\footnotetext{
${ }^{1}$ De aquí en diante DRAG.

2 "Don Alfredo Nan de Allariz, Secretario de la "Asociación iniciadora y protectora de la Academia Gallega" Certifico: Que en la Junta celebrada el día primero de los corrientes, fué discutido y aprobado este Reglamento, y para constancia lo firmo con el Visto Bueno del señor Presidente. Habana, 15 de junio de 1905 . Vto. Bno. El Presidente, Manuel Curros Enríquez. El Secretario, Alfredo Nan de Allariz" (Reglamento... 1905: 23).

${ }^{3}$ Arquivo da Real Academia Galega. Correspondencia 1905. Rexistros 1/250.
} 
institución imos tendo noticia do material que chega á institución con destino ao dicionario.

A primeira noticia desta achega de material procede da Acta de Xunta ordinaria do 30 de decembro de 1905 e dáse conta da chegada do Vocabulario de Pintos; na acta da Xunta de goberno correspondente o 12 de xaneiro de 1906 pode lerse "Se acordó dar las gracias al señor Lence Guintián por su envío de adivinanzas y refranes en gallego".

$\mathrm{Na}$ acta de Xunta ordinaria do 21 de marzo de 1907: "Se hizo saber a la Academia que el Sr. Cabeza de León de Santiago, había hecho donación de buen número de papeletas con voces gallegas para el Diccionario, agradeciendose por todos tan valioso donativo".

Son estas algunhas mostras do material que se utilizou para a redacción do dicionario académico e neste contexto de arrecada de material é onde se insiren os Vocabularios que estudamos.

\section{O VOCABULARIO DE PAYZAL}

Este vocabulario, como xa dixemos, foi publicado no ano 1994 por Manuel Ferreiro, nun artigo no que se describe polo miúdo o manuscrito. Polo que respecta á data de chegada deste manuscrito á Academia nada sabemos, pois a súa recepción non figura nos libros rexistro de entradas e tampouco se fai referencia a el nas Actas académicas nin no Boletín da Real Academia Galega. Do autor e do posuidor do manuscrito (José Baltar), xa Manuel Ferreiro subliñou no artigo citado que fora imposible atopar datos.

Trátase dun vocabulario dunhas 900 entradas aproximadamente, no que apenas existen definicións propiamente ditas; xeralmente son equivalencias acompañadas ou non dalgunha explicación. Canda o manuscrito hai dúas folliñas que non pertencen a el e nas que pode lerse: "letra D / Payzal No se copio mas/ que hasta esta letra/ inclusive"; e na outra: "El Diccionario no trae la letra B".

Probablemente estamos ante unha indicación relacionada co DRAG, que nos levaría a pensar que esta obra foi copiada e trasladada aos borradores de redacción.

$\mathrm{Na}$ edición impresa do DRAG a referencia ao Vocabulario de Payzal de forma explícita só aparece en 4 voces, e esta referencia faise de maneira diferente en cada unha delas; así temos:

\begin{tabular}{|l|l|}
\hline \multicolumn{1}{|c|}{ Payzal } & \multicolumn{1}{c|}{ DRAG } \\
\hline $\begin{array}{l}\text { ADRO. (El muro o } \\
\text { pared que lo divide o } \\
\text { cierra): Barbacana. }\end{array}$ & $\begin{array}{l}\text { ADRO. El muro o pared que } \\
\text { lo divide o cierra. Barbacana. } \\
\text { BENITO VICENTE PAYZAL. } \\
\text { Vocabulario Gallego-Castella- } \\
\text { no. ms. }\end{array}$ \\
\hline $\begin{array}{l}\text { ALCOBA (sobre la } \\
\text { escalera y otra parte } \\
\text { semexante): Cama- } \\
\text { reta. }\end{array}$ & $\begin{array}{l}\text { ALCOBA. "Sobre la escalera } \\
\text { y otras partes semejantes, } \\
\text { camareta." PAYZAL. Vocabu- } \\
\text { lario gallego-castellano. }\end{array}$ \\
\hline $\begin{array}{l}\text { ALXÓUXERE (lo } \\
\text { que tiene dentro para } \\
\text { que suene): Escrupu- } \\
\text { lillo. }\end{array}$ & $\begin{array}{l}\text { ALJOUJERE. Dice Payzal } \\
\text { que también se llama así al } \\
\text { escrupulillo o bolita metálica } \\
\text { que tiene dentro el cascabel } \\
\text { para que suene. }\end{array}$ \\
\hline $\begin{array}{l}\text { CAPARUZA/CAPI- } \\
\text { LLO (de paja o de } \\
\text { otra cosa): Gallaruza. }\end{array}$ & $\begin{array}{l}\text { CAPARUZA. s. f. Gallaruza. } \\
\text { Vestido con capucha usado } \\
\text { por los montañeses. Abonado } \\
\text { por Paizal. Lo mismo que } \\
\text { CAPILLO. }\end{array}$ \\
\hline
\end{tabular}

Parece, pois, escasa a presenza de Payzal na obra académica; agora ben, do cotexo do vocabulario co DRAG despréndese que esta foi máis abondosa, pois é facilmente rastrexable a pegada de Payzal noutras voces nas que non figura como fonte pero que repiten case exactamente as definicións do manuscrito. Así, por exemplo, podemos ver:

\begin{tabular}{|l|l|}
\hline \multicolumn{1}{|c|}{ Payzal } & \multicolumn{1}{c|}{ DRAG } \\
\hline $\begin{array}{l}\text { ABARASA (que se } \\
\text { pone a la madeja para } \\
\text { que no se enrede, } \\
\text { como es costal): } \\
\text { Cuenda. }\end{array}$ & $\begin{array}{l}\text { ABARASA.- s. f. Cuerda } \\
\text { delgada con que se ata la made- } \\
\text { ja para que no se enrede. Lo } \\
\text { mismo que COSTAL. }\end{array}$ \\
\hline $\begin{array}{l}\text { AGURUMELAR } \\
\text { (las cebollas, ajos, } \\
\text { centeno etc.): Grillar. } \\
\text { Tallecer. Entallecer. }\end{array}$ & $\begin{array}{l}\text { AGURUMELAR v. n. Grillar, } \\
\text { tallecer, entallecer, como las } \\
\text { cebollas, los ajos, los cereales, } \\
\text { etc. V. AGRELAR en sus cinco } \\
\text { primeras acepciones. }\end{array}$ \\
\hline $\begin{array}{l}\text { ALMA (los palos o } \\
\text { cañas que cruzan la } \\
\text { colmena): Trencas. }\end{array}$ & $\begin{array}{l}\text { ALMA Trenca. El palo o caña } \\
\text { que cruza la colmena para } \\
\text { sostener los panales. }\end{array}$ \\
\hline
\end{tabular}

\section{O VOCABULARIO DE PINTOS}

Cómpre salientar que, a diferenza do vocabulario de Payzal, neste caso si que sabemos cando pasou a formar parte dos fondos bibliográficos da Real Academia Galega.

Temos noticia da chegada do manuscrito do vocabulario de Xosé Manuel Pintos na Acta 
correspondente á Xunta ordinaria que tivo lugar o 30 de decembro de 1905:

Se nombraron Académicos correspondientes a los Srs.: D. Jesus Rivas Folla de Tuy, D. José Ma Moar Fandiño de Santiago y D. Román Pintos de Pontevedra. Acordándose ademas dar a este correspondiente un voto de gracias por el donativo hecho a la Academia del Diccionario gallego que dejó inedito el ilustre poeta gallego D. Juan M. Pintos ${ }^{4}$.

É un vocabulario que contén unhas sete mil voces ordenadas alfabeticamente presentadas en dúas columnas "castelán" - "galego". As voces galegas aparecen definidas na maior parte das veces pola súa equivalencia castelá, e con menor frecuencia pola equivalencia acompañada dunha breve definición ou ben dunha paráfrase aclaratoria do significado. Sobre a data da súa confección Marga Neira e Xesús Riveiro, na edición do manuscrito (1992), achégannos que podería estar ó redor de 1865.

Os redactores do DRAG botaron man do manuscrito de Xoán Manuel Pintos para a elaboración do texto académico e deixaron constancia da utilización deste material en moitas voces (aproximadamente unhas cincuenta) que teñen a Pintos como autoridade para aboalas en todas as súas acepcións ou ben nalgunha delas.

As referencias explícitas a Pintos aparecen de seis maneiras diferentes:

ADOITO. "Se usa con el verbo ser, v.g: non me é adoito; no se me adapta, no me está bien." JUAN MANUEL PINTOS. Breve Diccionario Gallego. ms.

ALGIVE. s. m. Pequeña porción de terreno cercado de muro. Abonada por Pintos.

AZOXOÑAR. v. a. "Avergonzarse, burlarse, hacer chacota, chufar." PINTOS.

BALUME. Broza del mar, según Pintos.

CASÉA. s. f. "Reunión de palangres para el pinche". PINTOS. Breve Diccionario Gallego.

CATÓN. De Catón, oblicuamente, según el Dic. inédito de Pintos.

Incluso nunha ocasión e dentro da mesma entrada atopamos dous xeitos distintos de citalo:

BUFO. "Junco amarocado." PINTOS.

BUFO. El plumín, flueco o lanilla de la espiga. Abonado por Pintos.
Das cincuenta ocasións que a obra académica remite a Pintos, vinte e unha responden a un lema coa súa correspondente ou correspondentes definicións, só coa documentación procedente do manuscrito (ASITIO, ALUMIÑO, CALCAÑEIRA, CAPIA, CANGALLEIRO...). Noutras 27 voces serve para autorizar algunha acepción (ADOITO, AXEXO, BALUME, CADRAZO...). E tamén se toma como autoridade a Pintos en 2 ocasións para inserir algunha variante dialectal con respecto á entrada (ARRASTRO, AMEAZA).

Polo que respecta ás posibles variacións que as definicións ou equivalencias achegadas por Pintos no seu Vocabulario sufriron no seu traslado ao DRAG, cómpre salientar que na maior parte dos casos apenas sufriron modificacións e pasaron a formar parte do corpus do dicionario académico tal e como as ofrecía Pintos, despois de seren adaptadas aos principios ortográficos que rexen o dicionario académico:

\begin{tabular}{|l|l|}
\hline \multicolumn{1}{|c|}{ Pintos } & \multicolumn{1}{c|}{ DRAG } \\
\hline $\begin{array}{l}\text { ALTIVAN. El tramo } \\
\text { que conduce a otro } \\
\text { piso, ó cubierta } \\
\text { diagonal. }\end{array}$ & $\begin{array}{l}\text { ALTIVÁN. s. m. El tramo que } \\
\text { conduce a otro piso o cubierta } \\
\text { diagonal. Abonado por Pintos. }\end{array}$ \\
\hline $\begin{array}{l}\text { CAPIA. s. f. Losa } \\
\text { que cubre un muro. }\end{array}$ & $\begin{array}{l}\text { CAPIA. s. f. Losa que cubre un } \\
\text { muro. Abonado por Pintos. }\end{array}$ \\
\hline
\end{tabular}

Nos casos en que se efectuaron modificacións, estas obedeceron na súa maior parte a cuestións de forma e técnica lexicográfica:

\begin{tabular}{|l|l|}
\hline \multicolumn{1}{|c|}{ Pintos } & \multicolumn{1}{|c|}{ DRAG } \\
\hline $\begin{array}{l}\text { ALGIVE. Dan en algunas } \\
\text { partes aquel nombre a una } \\
\text { porción pequeña de terre- } \\
\text { no cercado de muro. }\end{array}$ & $\begin{array}{l}\text { ALGIVE. s. m. Pequeña } \\
\text { porción de terreno cercado } \\
\text { de muro. Abonada por }\end{array}$ \\
Pintos.
\end{tabular}

Noutros casos os cambios son froito dunha mellora na redacción:

\begin{tabular}{|l|l|}
\hline \multicolumn{1}{|c|}{ Pintos } & \multicolumn{1}{c|}{ DRAG } \\
\hline $\begin{array}{l}\text { ATILLO. El nudo que } \\
\text { dan los labradores con } \\
\text { las mimbres en la vid, } \\
\text { cañas, etc }\end{array}$ & $\begin{array}{l}\text { ATILLO. s. m. agric. El } \\
\text { nudo de mimbre que dan los } \\
\text { labradores a la vid, cañas, etc. } \\
\text { Abonado por Pintos. }\end{array}$ \\
\hline
\end{tabular}

Outra das modificacións salientables é a corrección do seseo que se realiza en:

\footnotetext{
${ }^{4}$ Acta de Xunta de Goberno (30/12/1905). Libro de Actas. Real Academia Galega.
} 


\begin{tabular}{|l|l|}
\hline \multicolumn{1}{|c|}{ Pintos } & \multicolumn{1}{c|}{ DRAG } \\
\hline $\begin{array}{l}\text { CABASIÑA. Calabacita } \\
\text { y una especie de pato de } \\
\text { mar. }\end{array}$ & $\begin{array}{l}\text { CABACINA. Una especie } \\
\text { de pato de mar. Abonado } \\
\text { por Pintos. }\end{array}$ \\
\hline
\end{tabular}

Outro dos cambios que se producen, afecta ao termo "calzóns" que no DRAG pasou a CALZÓS:

\begin{tabular}{|l|l|}
\hline \multicolumn{1}{|c|}{ Pintos } & \multicolumn{1}{c|}{ DRAG } \\
\hline $\begin{array}{l}\text { CALZONS. Los saquitos } \\
\text { o bolsas donde tiene las } \\
\text { huevas la pescada. }\end{array}$ & $\begin{array}{l}\text { CALZÓS. s. m. pl. Los } \\
\text { saquitos o bolsas donde } \\
\text { tiene las huevas la pescada. } \\
\text { Abonada por Pintos. }\end{array}$ \\
\hline
\end{tabular}

Un caso de mala lectura, xa destacado polos editores do Vocabulario é:

\begin{tabular}{|l|l|}
\hline \multicolumn{1}{|c|}{ Pintos } & \multicolumn{1}{c|}{ DRAG } \\
\hline $\begin{array}{l}\text { ALLOADA. Pastel, } \\
\text { amasijo. }\end{array}$ & $\begin{array}{l}\text { ALLONDA. s. f. Pastel, ama- } \\
\text { sijo. Abonado por Pintos. }\end{array}$ \\
\hline
\end{tabular}

Outro caso que merece a nosa atención é o de ANTEPEITO, pois non aparecía definido nesta voz no vocabulario de Pintos senón que nos remitía á entrada GUANTES. No DRAG trasladouse a definición que Pintos recollía baixo a entrada GUANTES e fixéronse as modificacións oportunas nas variantes. Así:

\begin{tabular}{|c|c|}
\hline Pintos & DRAG \\
\hline $\begin{array}{l}\text { ANTEPEITO. V. Guantes. } \\
\text { GUANTES. Guantes, gra- } \\
\text { tificación que dá el forero } \\
\text { o recipiente al aforante, y } \\
\text { se llama también encama- } \\
\text { llo, conrogo, antepeito }\end{array}$ & $\begin{array}{l}\text { ANTEPEITO. Guantes. } \\
\text { Gratificación que da el } \\
\text { forero o recipiente al afo- } \\
\text { rante, y se llama también } \\
\text { CONROGO, ENCAMA- } \\
\text { LLO y GUANTES. Abon. } \\
\text { por Pintos. }\end{array}$ \\
\hline
\end{tabular}

En liñas xerais podemos dicir que a maior parte das ocasións en que se remite a Pintos se conservan case sen modificacións os termos do seu vocabulario e que todas as remisións se fan ao Vocabulario inédito. Non sendo no caso de AGULLA, que co significado que aparece no DRAG non está recollida no Vocabulario.

\begin{tabular}{|l|l|}
\hline \multicolumn{1}{|c|}{ Pintos } & \multicolumn{1}{c|}{ DRAG } \\
\hline $\begin{array}{l}\text { AGULLA. } \\
\text { Aguja. }\end{array}$ & AGULLA. En los puentes, llámase así \\
al espolón o tajamar, según Pintos.
\end{tabular}

Neste caso podemos estar ante un erro de atribución da fonte, pois quen recolle estes significados para Agulla é Payzal:

Agulla (de puente): Espolón

Agulla (de puente): Tajamar
Ata agora estivemos vendo aqueles casos en que o DRAG facía unha referencia expresa a Pintos, pero ao longo das páxinas deste dicionario fomos vendo que a presenza do manuscrito de Pintos estaba en máis voces que aquelas en que se salientaba de forma explícita. Así, por exemplo:

\begin{tabular}{|l|l|}
\hline \multicolumn{1}{|c|}{ Pintos } & \multicolumn{1}{c|}{ DRAG } \\
\hline $\begin{array}{l}\text { ALGODON. Algodón y } \\
\text { la lanilla que tienen las } \\
\text { cuerdas de la zanfona } \\
\text { para que la rueda hiera } \\
\text { en ella. }\end{array}$ & $\begin{array}{l}\text { ALGODÓN. La lanilla que } \\
\text { tienen las cuerdas de la } \\
\text { zanfona para que la rueda } \\
\text { hiera en ella. }\end{array}$ \\
\hline $\begin{array}{l}\text { ALMORZO JANTADEI- } \\
\text { RO. Almuerzo fuerte, } \\
\text { que tiene honores de } \\
\text { comida. }\end{array}$ & $\begin{array}{l}\text { ALMORZO JANTADEI- } \\
\text { RO. Almuerzo fuerte, que } \\
\text { tiene honores de comida. }\end{array}$ \\
\hline $\begin{array}{l}\text { CABANA. Se aplica a la } \\
\text { vaca que tiene las hastas } \\
\text { horizontales hacia delan- } \\
\text { te en forma de tenazas. }\end{array}$ & $\begin{array}{l}\text { CABANA. Aplícase a la } \\
\text { vaca que tiene las astas } \\
\text { horizontales hacia adelante } \\
\text { en forma de tenaza. }\end{array}$ \\
\hline $\begin{array}{l}\text { CANÉ. Juego de naipes } \\
\text { parecido al monte. }\end{array}$ & $\begin{array}{l}\text { CANÉ. Juego de naipes } \\
\text { parecido al monte. }\end{array}$ \\
\hline $\begin{array}{l}\text { CANGRO. Travesero } \\
\text { sobre que asientan las } \\
\text { ripias. }\end{array}$ & $\begin{array}{l}\text { CANGRO. s. m. Carp. Tra- } \\
\text { vesero sobre que asientan } \\
\text { las ripias. }\end{array}$ \\
\hline $\begin{array}{l}\text { CARAPUCHA. Caperu- } \\
\text { za, capita de junco que } \\
\text { cubre la cabeza y cae } \\
\text { sobre los hombros. }\end{array}$ & $\begin{array}{l}\text { CARAPUCHA. Caperuza. } \\
\text { Pequeña capa de junco que } \\
\text { cubre la cabeza y cae sobre } \\
\text { los hombros }\end{array}$ \\
\hline
\end{tabular}

Relación de voces que no dicionario académico están aboadas por Pintos:

ADOITO. "Se usa con el verbo ser, v.g: non me é adoito; no se me adapta, no me está bien." JUAN MANUEL PINTOS. Breve Diccionario Gallego. ms.

AFORADO, DA. [...] "Preparado, acondicionado el envase con buen líquido." PINTOS. Breve Diccionario Gallego, ms.

AGULLA. En los puentes, llámase así al espolón o tajamar, según Pintos.

ALGIVE. s. m. Pequeña porción de terreno cercado de muro. Abonada por Pintos.

ALLONDA. s. f. Pastel, amasijo. Abonado por Pintos. ALTIVÁN. s. m. El tramo que conduce a otro piso o cubierta diagonal. Abonado por Pintos.

ALUMIÑAR. v. a. Inspirar, iluminar, persuadir. Abonada por Pintos.

ALUMIÑO. s. m. Inspiración, estro. Abonada por Pintos.

AMANTEIGADO, DA. [...] fig. Zorro, astuto, disimulado. Abonado por Pintos.

AMEAZA. Señal que hace temer alguna cosa; cosa que parece amenazar. 
Var: AMENAZA y según Pintos, AMEAZO y AMEZO.

AMOLEGAR. Abollar, ablandar, entibiar. Abonada por Pintos.

ANTEPEITO. Guantes. Gratificación que da el forero o recipiente al aforante, y se llama también CONROGO, ENCAMALLO y GUANTES. Abon. por Pintos. APOUTAR. v. a. Aprontar, pechar. Abonado por Pintos.

ARRASTRO. Var: ARRASTO, según Pintos.

ARRENDAR. Ponerse en peligro. Abonado por Pintos.

ASITIO. s. m. Terreno unido a la casa. Abonado por Pintos.

ATEIRÓ. s. m. agric. El palopuesto en el yugo donde prende la cuerda por donde tira la segunda yunta. Abonado por Pintos.

ATILLO. s. m. agric. El nudo de mimbre que dan los labradores a la vid, cañas, etc. Abonado por Pintos.

ATOBADO. adj. Escondido, oculto en un escondrijo. Abonado por Pintos.

ATOBARSE. Ocultarse; meterse en el tobo. Abonado por Pintos.

ATOUTIÑAR. v. a. Andar a tientas. Abonado por Pintos.

ATRIBULARSE. Equivocarse, confundirse. Abonada por Pintos.

AVILIR. v. a. Envilecer, según Pintos.

AXEXO. Entre luces, lubricán. Abonado por Pintos.

AZOXOÑAR. v. a. "Avergonzarse, burlarse, hacer chacota, chufar" PINTOS.

BALLÓN. s. m. El rancio y color amarillo que cobra la sardina salada de mucho tiempo. Abonado por Pintos.

BALSEIRO. Flojo, de poca sustancia. Abonado por Pintos.

BALUME. Broza del mar, según Pintos.

BÉRTOLOS. s. m. pl. Bártulos. Enseres que se manejan. Abonado por Pintos.

BIQUEIRA. s. f. Canaleja, canalita. Abonada por Pintos.

BOCHA. Burbuja, según Pintos.

BOIRA. s. f. Pocito, hoyo que forma la lluvia en los sembrados. Abonado por Pintos.

BOTAFUMEIRO. s. m. Incensario. Abonado por Pintos.

BRECA. Herida, brecha, abertura. Abonada por Pintos.

BUFO. "Junco amarocado" PINTOS.

BUFO. El plumín, flueco o lanilla de la espiga. Abonado por Pintos.

CABACIÑA. Una especie de pato de mar. Abonado por Pintos.

CADRAZO. Escobajo, según Pintos.

CALCAÑEIRA. s. f. Calcañar, cimiento, juicio. Abonada por Pintos.
CALZÓS. s. m. pl. Los saquitos o bolsas donde tiene las huevas la pescada. Abonada por Pintos.

CAMARZO. s. m. Reprimenda. Peluca, reprensión acre y severa. Abonado por Pintos.

CANGALLEIRO, RA. adj. Lo que está desparramado. Abonado por Pintos.

CANO. bot. Pezón en las frutas, rabillo, tallo. Abonado por Pintos.

CAPELA. "Cada una de las mantillas de lana que forman al cardarla, y para que se dulcifique untan el cardador con aceite. Mantilla" PINTOS.

CAPIA. s. f. Losa que cubre un muro. Abonado por Pintos.

CAPIAR. v. a. Poner losas para cubrir un muro. Abonado por Pintos.

CARABUÑA. Testículo, según Pintos.

CARGA. En la Puebla se entiende por 24 ferrados de maíz nuevo en espiga. Abonado por Pintos.

CARROÑA. Cuerpo muerto. Espectro. Abonado por Pintos.

CARROUCHA. Según Pintos, la cucaracha.

CASÉA. s. f. "Reunión de palangres para el pinche" PINTOS. Breve Diccionario Gallego.

CATÓN. De catón, oblicuamente, según el Dic. inédito de Pintos.

\section{O VOCABULARIO DE PONDAL}

Cómpre destacar que o manuscrito do $\mathrm{Vo}$ cabulario gallego-castellano de Eduardo Pondal (Gómez Clemente / Arias Freixedo 1990) forma parte dos fondos bibliográficos da Real Academia Galega desde o ano 1908, como así se desprende da lectura da Acta de Xunta ordinaria celebrada pola corporación o 23 de marzo de 1908:

Se dio cuenta de las comunicaciones enviadas y recibidas, entre estas de una del Académico de Número D. Eduardo Pondal a la que acompañaba una extensa lista de vocablos vulgares y topónimos peculiares de la comarca de Bergantiños.

Levaba xa, pois, o DRAG algo máis de dous anos en proceso de elaboración, e parece responder este envío do manuscrito por parte de Pondal aos chamamentos que desde a Institución se facían solicitando a colaboración na achega de material léxico para a redacción do dicionario, pois pretendíase que este recollese o maior número de termos e que abranguese todo o territorio. Pouco antes do mandado de Pondal a Academia, na Xunta ordinaria do 28 de setembro de 1907, expresaba:

(...) los trabajos del Diccionario, momentaneamente detenidos por las vacaciones de verano, 
comenzarían de nuevo para continuar obra tan necesaria que no es, como muchos impacientes creen, cosa breve, ni obra de uno o varios solamente. Que el Diccionario se haría como debe hacerse y no como algunos (no pertenecientes a la Academia) con desconocimiento de lo que son estas cosas, se permiten aconsejar. Que tampoco será obra exclusiva de la Academia y que, aun cuando así lo fuera, nunca merecería las censuras que, creyéndola así, le han dirigido anticipadamente los que ensalzan en cambio la meritísima obra unipersonal de los Rodríguez, Cubeiro y Valladares, y juzgan sin valor la que pudieran hacer juntos todos los señores académicos; pero no será así; la obra ha de ser colectiva y de toda la región para lo que en breve continuará el envío de papeletas para ser devueltas cubiertas y que no debe llamar la atención de nadie el que en ellas figuren aun las voces mas comunes y contenidas ya en los diccionarios, pues es con objeto de saber si son generales en toda la región y si en alguna localidad tiene alguna otra acepción que no sea conocida.

No referente aos envíos de papeletas realizados pola Academia, tamén Pondal colaborou, pois consta (segundo puxeron de manifesto os editores do texto, Clemente e Arias Freixedo) que devolveu as papeletas correspondentes aos cadernos $1^{\circ}, 2^{\circ}, 3^{\circ}$, entre maio e novembro de 1908 , é dicir, con posterioridade ao envío do manuscrito. A diferenza, pois, dos dous manuscritos de Pintos e de Payzal, o manuscrito que achega Pondal constitúe un repertorio de léxico contemporáneo aos redactores.

Cinguíndonos xa ao manuscrito debemos indicar que consta de 60 páxinas nas que se inclúe léxico común e mais unha serie de topónimos do val de Ponteceso (a esta parte dedica o autor tan só as oito páxinas, que no volume encadernado son as últimas e ademais son follas de meirande tamaño ca as dedicadas á definición de vocábulos). Ao igual ca os vocabularios anteriores o criterio de definición vén dado pola equivalencia castelá do termo galego e nalgúns casos acompáñase cunha explicación coa que se complementa ou puntualiza o significado dalgunha palabra.

Canda o manuscrito gárdase unha folliña co seguinte texto: "Copiadas las letras A, B, C". Polo que respecta ás referencias explícitas a Pondal no DRAG cómpre salientar que só se rexistran cinco entradas coa súa autoridade:

\begin{tabular}{|c|c|}
\hline Pondal & DRAG \\
\hline $\begin{array}{l}\text { BRIZOS. Especie de } \\
\text { mente acuática, que } \\
\text { vegeta casi sumergida } \\
\text { en las aguas de los } \\
\text { pequeños riachuelos } \\
\text { de la comarca de Ber- } \\
\text { gantiños. Son muy } \\
\text { aromáticas y despi- } \\
\text { den un olor agradable } \\
\text { cuanto penetrante. }\end{array}$ & $\begin{array}{l}\text { BRIZO s. m. bot. Planta } \\
\text { perteneciente a la familia de las } \\
\text { umbelíferas, parecida al berro; } \\
\text { flor amarilla o blanca, tallo } \\
\text { hueco: crece a las márgenes de } \\
\text { la corriente que inunda el suelo } \\
\text { de las gavias. Por el verano } \\
\text { sirve de pasto al ganado. Pon- } \\
\text { dal la describe así: "Especie de } \\
\text { menta acuática, que vegeta casi } \\
\text { sumergida en las aguas de los } \\
\text { pequeños riachuelos de la co- } \\
\text { marca de Bergantiños. Es muy } \\
\text { aromática, y despide un olor } \\
\text { agradable cuanto penetrante" }\end{array}$ \\
\hline $\begin{array}{l}\text { CADUIRA. Agujero } \\
\text { abierto en el fondo } \\
\text { de las lanchas o botes } \\
\text { para dar salida al } \\
\text { agua, y también el } \\
\text { tapón de corcho o } \\
\text { madera para cerrarlo. }\end{array}$ & $\begin{array}{l}\text { CADUIRA s. f. Agujero abier- } \\
\text { to en el fondo de las lanchas, } \\
\text { botes, etc., para dar salida al } \\
\text { agua, y también el tapón de } \\
\text { corcho o madera para cerrarlo. } \\
\text { Abonado por Pondal. }\end{array}$ \\
\hline $\begin{array}{l}\text { CALMUZO. Calor } \\
\text { fatigoso y pesado, } \\
\text { acompañado de gran- } \\
\text { de calma. }\end{array}$ & $\begin{array}{l}\text { CALMUZO s. m. "Calor fati- } \\
\text { goso y pesado acompañado de } \\
\text { grande calma". Pondal. }\end{array}$ \\
\hline $\begin{array}{l}\text { CANDÁMIA, CAN- } \\
\text { DAMIO. Se dice } \\
\text { del hombre o mujer, } \\
\text { largos y desgarbados. }\end{array}$ & $\begin{array}{l}\text { CANDAMIO adj. Dícese de la } \\
\text { persona muy alta y desgarbada. } \\
\text { Abonado por Pondal. }\end{array}$ \\
\hline $\begin{array}{l}\text { CAROAL. Morroco- } \\
\text { tudo. Esta mazancéira } \\
\text { dou est'ano unha ma- } \\
\text { záns caroáles. Levéi } \\
\text { un cróque caroal. }\end{array}$ & $\begin{array}{l}\text { CAROAL s. m. Morrocotudo. } \\
\text { De mucha importancia. Abona- } \\
\text { do por Pondal. }\end{array}$ \\
\hline
\end{tabular}

Como podemos ver, en ningún dos cinco casos se fai referencia ao Vocabulario manuscrito, aínda que como estas referencias a Pondal aparecen a partir do caderno 22 , é moi probable que si fosen tomadas deste Vocabulario.

Non obstante e tal e como ocorría con Payzal e Pintos a pegada de Pondal pode rexistrarse nalgunhas outras voces que non levan a súa autoridade:

\begin{tabular}{|l|l|}
\hline \multicolumn{1}{|c|}{ Pondal } & \multicolumn{1}{c|}{ DRAG } \\
\hline $\begin{array}{l}\text { CALUGA, A. Nombre } \\
\text { jocoso de la cabeza y de } \\
\text { la nuca. }\end{array}$ & $\begin{array}{l}\text { CALUGA Nombre jocoso } \\
\text { de la cabeza y de la nuca. }\end{array}$ \\
\hline $\begin{array}{l}\text { CAROLA, CAROLAS. } \\
\text { Piñas del pino manso de } \\
\text { piñones comestibles. }\end{array}$ & $\begin{array}{l}\text { CAROLA s. f. La piña del } \\
\text { pino manso, la que da los } \\
\text { piñones comestibles. Var: } \\
\text { CAROCA en su primera } \\
\text { acep. y CAROZA. }\end{array}$ \\
\hline
\end{tabular}




\begin{tabular}{|l|l|}
\hline $\begin{array}{l}\text { BARDA. Cierta extensión } \\
\text { de un sembrado de trigo } \\
\text { maduro ya para ser sega- } \\
\text { do. Farruco tén unha bóa } \\
\text { barda de trigo. }\end{array}$ & $\begin{array}{l}\text { BARDA agric. Cierta ex- } \\
\text { tensión de un sembrado de } \\
\text { trigo maduro, que puede } \\
\text { ya segarse. } \\
\text { Ven a maturidade, } \\
\text { vosa miés verdecente; } \\
\text { Diante de vos ondea } \\
\text { a barda de ouro ardente... }\end{array}$ \\
\hline $\begin{array}{l}\text { CANLE Garganta a tajo } \\
\text { de una montaña. El cazo } \\
\text { de un molino }\end{array}$ & $\begin{array}{l}\text { CANLE 5. La garganta o } \\
\text { tajo de una montaña. }\end{array}$ \\
\hline $\begin{array}{l}\text { CABANA. Cabaña de } \\
\text { forma cónica, hecha de } \\
\text { pinos delgados, y cubierta } \\
\text { de caña seca de maíz o de } \\
\text { trigo, para resguardar este } \\
\text { forraje de la lluvia, y aún } \\
\text { para dormir o hacer guar- } \\
\text { dia dentro, en caso dado. }\end{array}$ & $\begin{array}{l}\text { CABANA Cabaña de for- } \\
\text { ma cónica, hecha de pinos } \\
\text { caña seca, para resguardar } \\
\text { el forraje de la lluvia y } \\
\text { aún para dormir o hacer } \\
\text { guardia dentro de ella }\end{array}$ \\
\hline $\begin{array}{l}\text { ANGOEIRO Zanja } \\
\text { profunda e irregular hecha } \\
\text { por las corrientes de las } \\
\text { aguas en las marismas de } \\
\text { Puenteceso. }\end{array}$ & $\begin{array}{l}\text { ANGOEIRO En Puen- } \\
\text { teceso, zanja profunda e } \\
\text { irregular hecha por las } \\
\text { corrientes de las aguas en } \\
\text { las marismas. }\end{array}$ \\
\hline $\begin{array}{l}\text { CACHAS Piñas de todas } \\
\text { clases secas y abiertas, } \\
\text { destinadas al uso del } \\
\text { hogar. }\end{array}$ & $\begin{array}{l}\text { CACHAS Las piñas de } \\
\text { todas clases, secas y abier- } \\
\text { tas, destinadas a encender } \\
\text { el fuego en la cocina. }\end{array}$ \\
\hline
\end{tabular}

\section{CONCLUSIÓNS}

A modo de conclusión cómpre salientar que a contribución destes vocabularios aínda que cuantitativamente parece pequena, debido fundamentalmente ao gran número de voces que recolle o DRAG, cualitativamente é moi importante, pois a achega deste material permitiu en moitas ocasións que voces ou acepcións do léxico común e popular quedasen rexistradas nun repertorio da envergadura do DRAG, co que iso significa, pois a través deste, outros dicionarios e vocabularios publicados con posterioridade, recolleron estas voces e permitiron que chegasen ata nós, que doutro xeito igual quedaban perdidas, coma moitas outras.

Podemos dicir, pois, que os tres vocabularios estudados contribuíron ao labor encomendado desde A Habana, obxectivo principal da institución académica desde a súa constitución; mágoa que tan grande proxecto quedase fanado poucos anos despois de encetarse, pois aínda que foron 27 cadernos entre os anos 1913 e 1928, a maior parte do dicionario estaba por publicar e con toda seguridade sen redactar.

\section{REFERENCIAS BIBLIOGRÁFICAS}

Arias Freixedo, Bieito / Xosé María Gómez Clemente (1990): “O Vocabulario Gallego-Castellano de Eduardo Pondal”, Cadernos de lingua 2, pp. 11-46.

Ferreiro, Manuel (1994),“Contribución á lexicografía histórica do galego: o vocabulario de Payzal”, Cadernos de lingua 9, pp. 55-88.

NeIra, Margarita / Xesús Riveiro (1992): Vocabulario gallego-castellano de Juan Manuel Pintos. A Coruña: Real Academia Galega (Colección Cadernos de lingua 5).

[Real] Academia Galega (1905): Reglamento de la Asociación Iniciadora y Protectora de la Academia Gallega. Habana: Imprenta y Papelería de Rambla y Bouza.

Seodne SÁnchez, Isabel (1999), "O primeiro diccionario da Real Academia Galega”, Cadernos de lingua 19 , pp. 65-84. 